Yves Charpak MD, Christian Blery MD,

Claude Chastang MD PHD, Mireille Szatan MD, Bruno FourgeauX MD

\title{
Prospective assessment of a protocol for selective ordering of preoperative chest $x$-rays
}

\begin{abstract}
Rouine preoperative chest $\mathrm{x}$-rays are still widely employed worldwide, although results of many studies do not support their broad utilization. A protocol for selective ordering of preoperative chest $\mathrm{x}$-rays, according to the patient's clinical status, medical history and scheduled surgery, was developed and implentented in a teaching hospital in Paris. The utilization of the protocol during a one-year period was evaluated. Eleven hundred and one chest $\mathrm{x}$-rays were ordered in 3866 patiends (28 per cent). Five hundred and sirty-eight $\mathrm{x}$-rays ( 52 per cent) were abnomal. One hundred and sixty-six (15 per cent) were considered useful by the anaesthetists, who took inio accoust the entire hospital course, whough only 51 (5 per cent) had an impact on the surgical plan or anaesthetic management. Among the 2765 parients who did not have a preoperative chest $x$-ray, two patients could have berrefited from the chest $x$-ray, in the view of anaesthetists. Chart review for the se two patients and for patients who had perioperative complications in the absence of a preoperative chest $\mathrm{x}$-ray revealed that no complications could be linked to the lack of preoperative chest $\mathrm{x}$-ray ordering. This study shows that the abandonment of routine ardering of preoperative chest $\mathrm{k}$-rays does not produce adverse effects on patient care.
\end{abstract}

\section{Key words}

ASSESSMENT, PREOPERATIVE: chest $x$-ray, protocol; COMPLICATIONS: intraoperative, postoperative.

From the Departement de Biostatistique et Informatique Médicale, Hôpital Saint-Louis, Paris, France, and the Département d'Anesthésiologie, Hôpital Rothchild, Paris, France.

Address correspondence to: Yves Charpak, Département de Biostatistique et Informatique Médicale, Hôpital Saint-Louis, 1 Av. Claude Vellefaux, 75475 Paris Cédex 10.

This work was supported by a grant from the INSERMCNAM Canvention and a grant from the Dircetion Générale de la Santé, Ministère de la Santé et de la Solidarité Nationale.
Routine preoperative chest $x$-rays have been previously suspected to be inefficient at several levels: inadequate technical quality of $x$-rays is not uncommon; ${ }^{1,2}$ unexpected abnormalities are rare ${ }^{3}$ and they seldom lead to initiation or modification of medical actions; ${ }^{4}$ the baseline value of preoperative chest $x$-rays could not be proved; ${ }^{5}$ decrease of preoperative ordering in some places was not followed by any increase of perioperative morbidity. ${ }^{6}$ These facts have led many to recommend abandonment of routine preoperative chest $x$-ray ordering. ${ }^{5,7,9}$

However, routine preoperative chest $x$-rays are still widely ordered. Fifty per cent of all radiologic procedures worldwide are chest $x$-rays, ${ }^{7}$ many of them being performed preoperatively. In France preoperative chest $\boldsymbol{x}$-rays are performed in 60 per cent of patients undergoing surgical procedures. ${ }^{8}$

Evaluation studies have also proved other routine preoperative tests to be of little benefit and selective ordering, based on clinical examination, medical history, and scheduled surgery, has been advocated to replace routine ordering. A protocol for selective ordering of 12 preoperative tests, including the chest $x$-ray, was developed by one of us (C. Bléry). We previously reported the assessment of its utilisation during one year in a teaching hospital. ${ }^{10}$

This paper reports results from this study dealing specifically with preoperative chest $x$-rays.

\section{Methods}

The study was conducted at Rothschild Hospital (Paris), a teaching hospital with 230 beds for adult general, orthopaedic, plastic, gynaecologic and obstetrical surgical procedures. All patients having operations or investigations under general or regional anaesthesia (but not local infiltration) from October 17, 1983 to October 15, 1984 were included in this study. Only data on the first operation or investigation for each patient during the study period were considered for analysis.

Chest $x$-rays were ordered after a full clinical history and examination had been taken. Indications for the ordering of preoperative chest $x$-rays were any lung 
diseases, any cardiovascular diseases, known malignant diseases, major surgical emergencies (e.g., peritonitis, multitrauma), current smoking history in patients more than 50 years old, immunodepression (malnutrition, steroid therapy, chemotherapy) and lack of a prior health examination in immigrants.

There were 44 physicians potentially involved in the ordering of preoperative chest $x$-rays: 22 anaesthetists, including ten full-time physicians and 12 residents, and 22 surgeons, including 11 full-time physicians and 11 residents. All were aware of the purpose of this study and gave their consent to use the protocol in all patients, but they remained free to depart from ordering recommendations. In practice, shest $x$-rays were mostly ordered by full-time anaesthetists for elective surgery (preanaesthetic visit) and by surgical residents for emergencies (hospital admission). All chest $x$-rays were ordered on special forms that were kept near a prominent display of the protocols

Anaesthetists completed a two-part data form specially designed for the study. This form was prospectively completed at each stage of care from the preanaesthesic visit to the recovery room and included data on clinical history and examination, scheduled and actual surgery, and preoperative testing. Chest $x$-rays findings (cardiothoracic ratio, parenchymal oedema, atelectasic or focal infiltrate, pleural abnormality) and their effect on surgical plan (cancellation, delay or modification), on pre- and peroperative therapy, on further investigations and on anaesthetic management were recorded prospectively. Chest $x$-rays findings and their effect on medical decisions were recorded as reported by the anaesthetist involved in patient care.

When the patient was discharged or was to have another procedure, the anaesthetist in charge of the patient provided further information on postoperative complications, test ordering, and outcomes, and was asked to give an opinion on the usefulness of the preoperative chest $x$-ray that had been ordered and on the potential usefulness of chest $x$-rays that had not, considering pre-, perand postoperative events.

After all data were collected, a computerized analysis was performed to assess the following elements:

1 Abnormality. Chest $x$-rays abnormalities were defined as any pleural or parenchymal abnormalities or cardiothoracic ratio equal to or greater than 0.5 .

2 Recommendation for ordering. Chest $x$-rays were recommended in the presence of indications for ordering, as described previously. Thus, chest $x$-rays could be (i) recommended and ordered, (ii) recommended but not ordered, (iii) not recommended and not ordered, and (iiii) not recommended but ordered.
3 Usefulness of ordered chest $x$-rays was defined as abnormal results that had an effect on surgical plan, on therapy, on anaesthetic management, or on further investigation.

4 Potential usefulness of not-ordered chest $x$-rays was defined as the occurrence of perioperative pulmonary or cardiovascular complications.

This automated assessment of usefu'ness or potential usefulness was compared to anaesthetists assessment. In addition, we assessed the relation between the usefulness of chest $x$-rays (evaluated by both methods) and ordering recommendations.

\section{Results}

The study included 3883 patients of whom 3866 had information available suitable for analysis. Characteristics of patients and operations are shown in Table I. A preoperative chest $x$-ray was ordered in 1101 patients (28 per cent). All ordered chest $x$-rays were performed.

\section{Abnormalities}

Half of the ordered chest $x$-rays were reported to be abnormal (568 out of 1101,52 per cent), among which 23 per cent (133 out of 568) were considered as unexpected by anaesthetists.

Table II displays chest $x$-rays abnormalities in relation to age. Four hundred and sixty patients had a cardiothoracic ratio $\geq 0.5$, but it was $\geq 0.55$ in only 156 patients, mainly in patients older than 55 or presenting with cardiac disease or hypertension. Atelectasis or focal infiltrate were observed mostly in patients with chronic obstructive pulmonary diseases, cardiopathy or in migrants without prior health examination. Oedema was mostly observed in patients with cardiac disease or acute aboominal diseases. Pleural abnormalities were mostly sequelae of previous pulmonary diseases. No lung cancer was detected in 150 heavy smokers $\geq 50$ years of age, and no pulmonary metastases were observed in 216 patients with malignant disease.

Impact of chest $\mathrm{x}$-rays on medical decisions and usefulness Chest $x$-rays led to modification of medical decisions in 51 patients (five per cent of 1101): surgical procedure was delayed or cancelled in three patients, treatment was instituted or modified in 21 patients and anaesthetic management was influenced in 27 patients. Only these 51 chest $x$-rays were considered useful by the computerized analysis, according to our previous definition.

In the view of the andesthetists, 166 preoperative chest $x$-rays were useful at some time during the hospital course (15 per cent of 1101), of which 42 chest $x$-rays were also found useful by automated analysis, 41 were normal chest 
TABLE $]$ Patients, surgical procedures and outcome

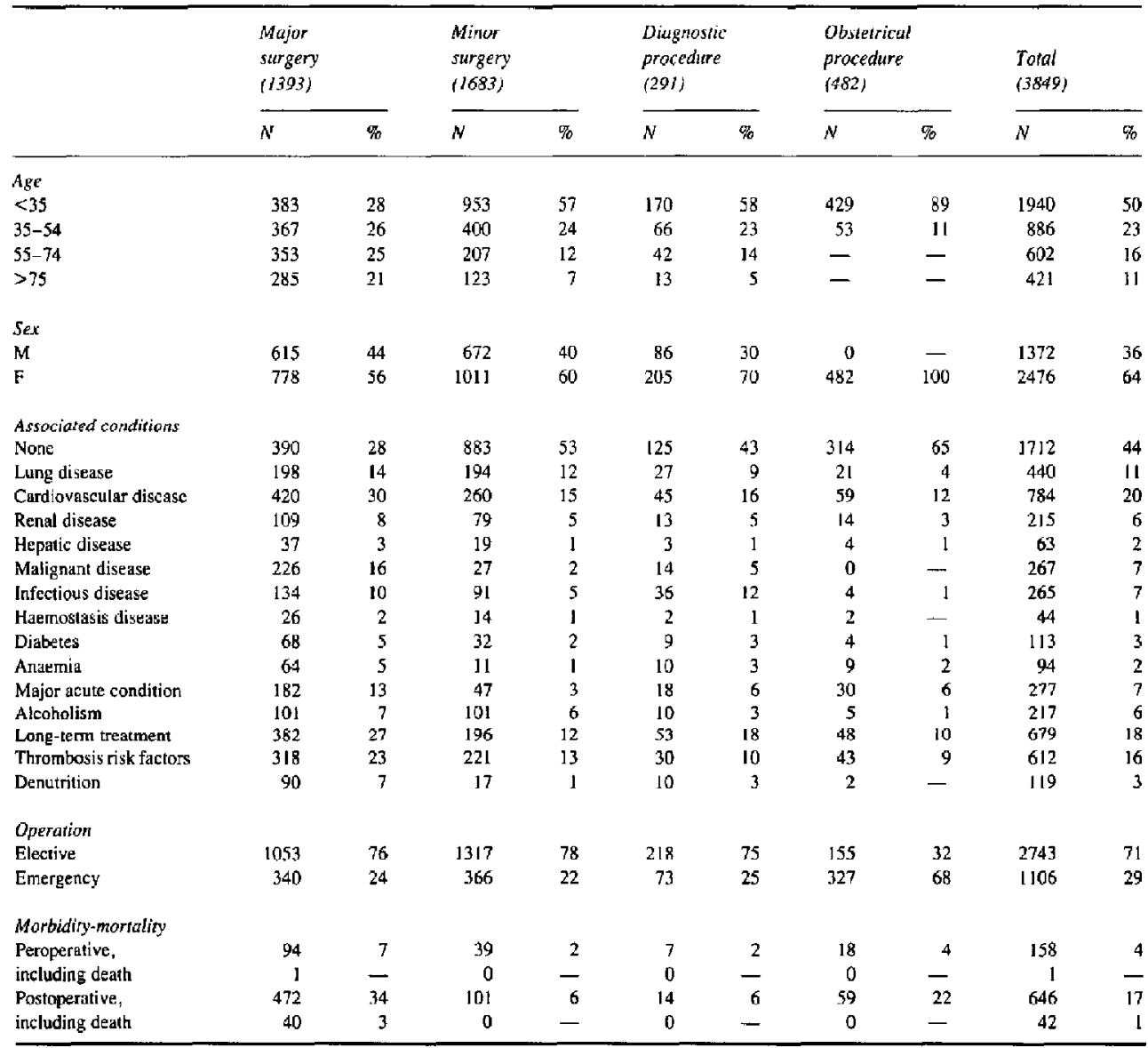

$x$-rays and 83 were abnormal chest $x$-rays without any reported impact on surgical or anaesthetic plan.

Potential usefulness of chest $x$-rays not performed

Twenty-seven hundred and sixty-five patients ( 72 per cent) had no preoperative chest $x$-rays. The anaesthetists felt that a chest $x$-ray would have been potentially useful in two patients: the first patient was a 43-year-old man, a smoker and an immigrant, who had had a prior health examination and who underwent an appendicectomy. He presented no pulmonary complication but experienced a postoperative fever. A postoperative chest $x$-ray was performed but it had no influence on the medical decisions. In fact, in this case, only the postoperative chest $x$-ray was useful to rule out a lung infection. The second patient was a 72-year-old man, with chronic obstructive pulmonary disease, who underwent a surgical procedure for neurological disease. He developed postoperative fever, pneumonia and respiratory insufficiency. Six postoperative chest $x$-rays were performed to assess therapy. In this case a preoperative chest $x$-ray should have been ordered, according to the protocol.

Based on occurrence of intra- or postoperative pulmonary or cardiovascular complications, automated analysis found that a chest $x$-ray would have been potentially useful in 19 patients. Chart review for each of these 
TABLE II Abnomalities in relation to age

\begin{tabular}{|c|c|c|c|c|c|c|c|c|c|}
\hline \multirow[b]{3}{*}{ Age } & \multirow[b]{3}{*}{$N$} & \multicolumn{4}{|c|}{ Cardiothoracic ratio } & \multirow{2}{*}{\multicolumn{2}{|c|}{$\begin{array}{l}\text { Parenchymal } \\
\text { abnormality }\end{array}$}} & \multirow{2}{*}{\multicolumn{2}{|c|}{$\begin{array}{l}\text { Pleural } \\
\text { abnormality }\end{array}$}} \\
\hline & & \multicolumn{2}{|c|}{$\geq 0.5$} & \multicolumn{2}{|c|}{$\geq 0.55$} & & & & \\
\hline & & $N$ & 90 & $N$ & $\%$ & $N$ & $\%$ & $N$ & $\%$ \\
\hline$<35$ & 147 & 17 & 12 & 7 & 5 & II & 7 & 5 & 3 \\
\hline $35-54$ & 227 & 56 & 25 & 7 & 3 & 24 & 11 & 17 & 8 \\
\hline $55-74$ & 393 & 164 & 42 & 43 & 11 & 40 & 10 & 36 & 9 \\
\hline$\geq 75$ & 329 & 223 & 68 & 99 & 30 & 65 & 20 & 35 & 11 \\
\hline Total & $1096^{*}$ & 460 & 42 & 156 & 14 & 140 & 13 & 93 & 8 \\
\hline
\end{tabular}

*Data on age were missing for 5 patients.

patients showed that a preoperative chest $x$-ray would not have helped to avoid complications or improve therapy.

Among the 44 deaths (out of 3866 patients), only one occurred in a patient that had no preoperative chest $x$-ray: an 82-year-old woman died after four days of postoperative coma, without any pulmonary or cardiac complication. Her death could not be linked to the lack of a preoperative chest $x$-ray.

Patients in whom a preoperative chest $x$-ray had not been ordered were those who had less per- or postoperative complications (Table III). The ordering of preoperative chest $x$-rays was more predictive of perioperative complications than was an abnormal result in patients who had a preoperative chest $x$-ray.

\section{Agreement between actual ordering and protocol recommendations}

According to the protocol recommendations, 1426 chest $x$-rays should have been ordered; 271 chest $x$-rays were ordered although they were not recommended, and 596 were not ordered although they were recommended.

Table I $V$ gives the rate of ordering of preoperative chest $x$-rays in all indications that were selected for the protocol. The low percentage of prescription for migrants is striking, but most of migrants were pregnant women.

Usefulness of ordered chest $\mathrm{x}$-rays according to protocol recommendations

In the view of the anaesthetists, 150 of 830 recommended chest $x$-rays were useful (18 per cent), however, only 16 of 271 non-recommended chest $x$-rays werc considered useful (six per cent).

Based on abnormalities with an impact on medical decisions, the computerized analysis found respectively 47 of 830 (six per cent) and four of 271 (1.5 per cent) cases.

\section{Postoperative chest $\mathrm{x}$-rays}

Twenty-four per cent of patients with preoperative chest $x$-rays had at least one chest $x$-ray during the postoperative period, especially when the preoperative chest $x$-ray showed oedema or atelectasis, or in patients older than 50 when pulmonary or cardiac complications occurred.

Two per cent of patients without a preoperative chest $x$-ray had at least one chest $x$-ray during the postoperative period.

\section{Diseussion}

This study confirms that routine ordering of preoperative chest $x$-rays can be abandoned without altering patient care, No death or pulmonary complication could be linked to the lack of preoperative chest $x$-ray ordering. Patients in whom preoperative chest $x$-rays were not ordered were also those who had fewer per- or postoperative complications. In only two situations did anaesthetists consider that a preoperative chest $x$-ray would have been potentially useful, but in onc case its ordering was in fact recommended by the protocol because of known pulmonary disease, and in the second case the potential usefulness was doubtful.

Selection of patients on the basis of clinical indications for chest $x$-ray ordering explains in part the high rate of observed abnormalities ( 52 per cent of performed chest $x$-rays). However, the abnormality rate is also greatly influenced by setting limits to normal range: raising the normal limit of the cardio-thoracic ratio from 0.50 to 0.55 reduced the overall rate of abnormal chest $x$-rays from 52 to 31 per cent. In fact, the abnormality yield is not in itself hclpful for the evaluation of test usefulness. What is meeded is a measure of the degree of abnormality usually assocjated with some action or decision related to the patient's care. Such definition of usefulness led to a large discrepancy between abnormality and usefulness rates in our study: nine per cent of the abnormal chest $x$-rays (51/568) had an impact on surgical and anaesthetic plans. Two retrospective studies dealt with impact of chest $x$-rays in patients with suspected chest disease. Thomsen ${ }^{4}$ 
TABLE IIl Complications related to ordering and tesults

\begin{tabular}{|c|c|c|c|}
\hline & \multicolumn{3}{|c|}{ Preoperative chest x-rays } \\
\hline & $\begin{array}{l}\text { Not ordered } \\
N=2765\end{array}$ & $\begin{array}{l}\text { Ordered } \\
\text { and normal } \\
N=533\end{array}$ & $\begin{array}{l}\text { Ordered } \\
\text { and abnormal } \\
N=568\end{array}$ \\
\hline Peroperative complications & $2.7 \%$ & $6.7 \%$ & $10.4 \%$ \\
\hline Postoperative pulmonary complications & $0.9 \%$ & $12.0 \%$ & $20.0 \%$ \\
\hline Pustoperative cardiac complications & $0.7 \%$ & $5.0 \%$ & $14.0 \%$ \\
\hline All complications & $10.0 \%$ & $39.0 \%$ & $52.0 \%$ \\
\hline Deaths & $0.03 \%$ & $1.6 \%$ & $9.2 \%$ \\
\hline
\end{tabular}

TABLE IV Rates of ordering for all indications selected in the protocol

\begin{tabular}{lrl}
\hline Indications & $N$ & Ordering \\
\hline Hypertension & 336 & $57 \%$ \\
Ischaemic cardiopathy & 152 & $82 \%$ \\
Nonischaemic cardiopathy & 99 & $71 \%$ \\
Other cardiovascular diseases & 149 & $46 \%$ \\
Asthma & 112 & $29 \%$ \\
Chronic obstructive pulmonary diseases & 117 & $79 \%$ \\
Other pulmonary diseuses & 214 & $71 \%$ \\
Major surgical emergencies & 55 & $87 \%$ \\
Malignant diseases & 268 & $81 \%$ \\
Snokers $>$ 50 years old & 203 & $74 \%$ \\
Migrants without priur health examination & 120 & $23 \%$ \\
\hline
\end{tabular}

found significant abnormalities on preoperative chest $x$-rays in 24 per cent of 695 patients with cardiopulmonary problems, but only two had changes in therapy. On the other hand, Haubeck ${ }^{11}$ identified 64 patients with suspecter cardiopulmonary disease; 24 of them had abnormal chest $x$-rays, 11 of whom had changes in therapy. Usefulness of preoperative chest $x$-rays was even greater in the view of anaesthetists ( 15 pcr cont of ordered chest $x$-rays), who took into account what happened during the hospital course. This could reflect some aspects of evaluation of uscfulness that are difficult to grapple with, such as importance of normal findings ( 41 normal chest $x$-rays were considened useful by anaesthetists), prognostic assessment, need for reassurance or different conception of usefulness ( 83 abnormal chest $x$-rays were considered useful by anaesthetists although they had no impact on pre- or peroperative medical decisions).

Although all potential prescriptors had given their consent to use the ordering protocol, ordering of the preoperative chest $x$-rays did not fit exactly with protocol recommendations. This shows that there is a gap between the acceptance of the idea of selective ordering and the utilization of the protocol recommendations, even in a research purpose. In addition, it is likely that the ordering protocol was not perfect. This is contirmed by the fact that some of the chest $x$-rays that were ordered although not recommended were found useful (six per cent in the view of anaesthetists and 1.5 per cent by automated analysis). Improvement of the ordering protocol could be achieved by taking into account other elements that are not easy to define simply (more detailed characteristics of patients in order to fit better with individual situations). However, the utilization of such an optimized but more complicated ordering protocol in routine medical activity might be more hazardous. The ordering protocol should then remain a guideline and not become standard for prescribing.

We acknowledge limitations of our study: the ideal study would have been a randomized comparative trial allocating patients to receive or not receive a routine preoperative chest $x$-ray. ${ }^{9}$ The end points would be death or major morbidity. As they are quite infrequent (overall mortality during hospital stay was 1.1 per cent in our study) and are expected to be weakly related to preoperative tests results, such a study would require too many patients to have a reasonable chance of showing a difference, even if it does exist.

It is, however, likely that sufficient scientific information was available before this study to permit abandonment of routine ordering of preoperative chest $x$-rays. It is then questionable whether implementing such a study was justified or whether further studies should be conducted, as they are quite costly and time consuming.

Our study provided the opportunity to experiment on the three stages that Fowkes and Roberts ${ }^{12}$ described to secure changes in test-ordering: the first stage is to introduce in surgical and anaesthetic departments the idea that routine preoperative ordering might be useless and to obtain a consensus among physicians; the second stage is the introduction of guidelines into clinical practice, with education of hospital stuff, and the third stage is the sustained implementation of the guidelines during the study period. Those guidelines may have been better accepted because they were part of a study than they would have been in another context. It seems that implementation of evaluation studies provides local opportunities to 
introduce changes in medical practice, even when the scientific necessity of the study is not obvious.

In conclusion, it is possible to abandon routine ordering of preoperative chest $x$-rays without undesirable effects on patient care and outcome. Implementing guidelines for the ordering of tests in a research context may facilitate their acceptance by clinicians.

\section{Acknowledgements}

We would like to thank Guy Frija, Professor of Radiology (Raymond Poincaré Hospital in Garches), and Philippe Grenier, Professor of Radiology (Beaujon Hospital in Clichy), for their helpful suggestions.

\section{References}

1 Abrams $H L$. The "overutilization" of $x$-rays. N Engl J Med 1979; 300: 1213-6.

2 Bekemeyer WB, Crapo RO, Calhoon S, Cannon CY, Clayton $P D$. Efficacy of chest radiography in a respiratory intensive care unit. A prospective study. Chest $1985 ; 88$ : 691-5.

3 Rucker $L$, Frye EB, Sraten $M A$. Usefulness of screening chest roentgenograms in preoperative patients. JAMA 1983; 250: 3205-11.

4 Thomsen HA, Gottlieb J, Madsen IK et al. Routine radiographic examination of the thorax prior to surgical intervention under general anaesthesia. Ugersk Laeger 1979; 140: 765-86.

5 National Study by the Royal College of Radiologists. Preoperative chest radiology. Lancet $1979 ; 2: 83-6$.

6 Roberts CJ, Fowkes FGR, Ennis WP, Mitcheil M. Possible impact of audit on chest $x$-ray requests from surgical wards. Lancet 1983; 2 : 446-8

7 Conception rationnelle des actes de radiodiagnostic. Rapport d'un groupe scientifique OMS sur les indications et les limites des principaux actes de radiodiagnostic. OMS, Rapports techniques, Genève, 1983; 689: 11-30.

8 Blery $C_{\text {r }}$ Charpak $Y$, Tiret $L$. Le choix des examens complémentaires préopératoires. In: Anesthésie et Réanimation. Conférence d'actualisation 1987. Ed. Comité Scientifique de la Société Françaisc d'Anesthésie Róanimation. Paris, 1987: 193-210.

9 Tape TG, Mushlin Al. The utility of routine chest radiographs. Ann Intern Med 1986; 104: 663-70.

10 Blery $C$, Charpak $Y$, Szatan $M$ et al. Evaluation of a protocol for selective ordering of preoperative tests. Lancet 1986; 1: 139-41.

11 Haubek A, Cold G. The indications and consequences of preoperative radiography of the thorax. Ugeskr Laeger $1978 ; 140 ; 772-3$.

12 Fowkes FGR, Roberts CS. Introducing guidelines into clinical practice. Effective Health Care $1984 ; 2 ; 83-7$.
Résumé

Le cliché thoracique préopératoire de routine est encore largement prescrit, bien que les résultats de nombreuses études permestent de douter de son intérêt. Unte stratégie de prescription sélective du cliché thoracique préopératoire à partir de l'interrogatoire, de l'examen clinique et de l'acte prévu a été définie et évaluée pendant un an dans un hôpital universitaire parisiert. 1101 clichès thoraciques préopérasoires ons èté réalisés chez les 3866 patients consécutifs inctus dans l'élude (28 pour cent). 568 cliché étaient anormaux ( 52 pour cent). 166 (15 pour cent) ont été jugés utiles par les anesthésistes à un moment quelconque de l' hospiralisation, alors que 5 I seulement (cinq pour cent) ont eu un impact sur les décisions chirurgicales ou anesthésiques pré ou peropératoires. Les anesthesistes ont regretté l'absence de cliché thoracique préopératoire chez deux patients parmi les 2765 qui n'en ont pas eu. Une analyse des dossiers médicaux a permis de vêrifier que l'absence du cliché thoracique préopératoire n'érair pas à l'origine de complica. tions cardiopulmonaires ou de décès chez tes patients concernés. En conciusion, ce travail montre que la prescription de routine du cliché thoracique préopéraroire peut ètre abandonnée au profit d"une prescription sélective sans altérer la sansé des patients. 